\title{
Studies of Leukocyte Kinetics by Liquid Scintillation Counting in Normal Individuals and in Patients with Chronic Myelocytic Leukemia*
}

\author{
Seymour Perry, $\dagger$ John H. Moxley III, $\ddagger$ George H. Weiss, and \\ Marvin ZeLen
}

(From the National Cancer Institute, National Institutes of Health, Bethesda, Md.)

Leukocyte kinetics have been investigated with the use of a number of different radioisotopic labels including ${ }^{32} \mathrm{P}$ as disodium acid phosphate and as diisopropylfluorophosphate $\left(\mathrm{DFP}^{32}\right)$, adenine${ }^{14} \mathrm{C}$, and guanine $(1-4)$. All of these have disadvantages that limit their usefulness. The ${ }^{32} \mathrm{P}$ labeled phosphate and the ${ }^{14} \mathrm{C}$ compounds readily exchange with corresponding body pools and hence are not pulse labels. The quality of their emissions does not permit precise radioautography so that kinetics of specific cell types cannot be followed. The use of $\mathrm{DFP}^{32}$ is limited because it does not label the early precursor cells. However, Athens and associates $(3,5,6)$ have obtained a great deal of valuable quantitative data using this label, particularly in defining the intravascular leukocyte compartments and intravascular survival time.

Since thymidine was first tritiated in 1955, it has become the most important tool for radioautographic studies of leukocyte dynamics (7-9). It has achieved this importance because it is a specific precursor for DNA and is exclusively and efficiently incorporated into DNA. After injection, the tritiated thymidine $\left({ }^{3} \mathrm{HTdR}\right)$ that is not incorporated is quickly catabolized to substances not utilizable for DNA synthesis and largely excreted. Negligible amounts of the label are found in the acid soluble pool or associated with RNA or protein when these are extracted by the usual techniques. This makes it an excellent tool for cytochemical studies (10). Since its beta emissions are of low energy, radioautographs with high resolution may be obtained.

* Submitted for publication September 7, 1965; accepted May 25, 1966.

$\dagger$ Address requests for reprints to Dr. Seymour Perry, Medicine Branch, National Cancer Institute, Bethesda, Md. 20014.

$\ddagger$ Present address: Peter Bent Brigham Hospital, Boston, Mass.
An important disadvantage in the use of tritiated thymidine for radioautography in the study of leukocyte kinetics is the fact that this technique is time consuming and presents a number of problems in interpretation (11). It occurred to th that liquid scintillation counting might be a very useful tool in the study of leukocyte kinetics with ${ }^{3} \mathrm{HTdR}$, particularly for quantitation.

The radioautographic data reported by Cronkite and his co-workers are the only studies in the literature of leukocyte kinetics in hematologically normal individuals and in patients with chronic myelocytic leukemia after injection with ${ }^{3} \mathrm{HTdR}$ $(11,12)$. The purpose of the present study is to report the results obtained in similar individuals given ${ }^{3} \mathrm{HTdR}$ and then followed by both liquid scintillation counting and radioautographic analysis.

\section{Methods}

Normal individuals. Since ${ }^{3} \mathrm{HTdR}$ has a long half-life and is a DNA label, its use should be limited to patients with a very limited life expectancy who are nonreproductive. In this part of the study the leukosyte kinetics in three patients admitted to the National Cancer Institute were investigated. All had localized malignancies and were considered to have life expectancies of no more than a few months. Pertinent patient data are given in Table I. The patients were in good nutritional status and essentially normal hematologically, as determined by complete blood counts and analyses of bone marrow aspirates. Two of the three patients had leukocyte counts at the outset slightly above the normal range, but these rapidly reverted to more normal levels.

Tritiated thymidine $\left({ }^{3} \mathrm{HTdR}\right.$, SA $1.9 \mathrm{c}$ per mmole), ${ }^{1}$ $100 \mu \mathrm{c}$ per $\mathrm{kg}$ body weight, was injected intravenously in a single dose. Peripheral blood samples of 25 to 30 $\mathrm{ml}$ were drawn just before the injection of the isotope and at predetermined intervals thereafter. Five per cent EDTA was used as the anticoagulant. Leukocyte counts were done using an electronic cell counter. ${ }^{2}$ Dif-

1 Schwarz BioResearch, Orangeburg, N. Y.

2 Coulter Electronics, Hialeah, Fla. 
TABLE I

Pertinent patient data

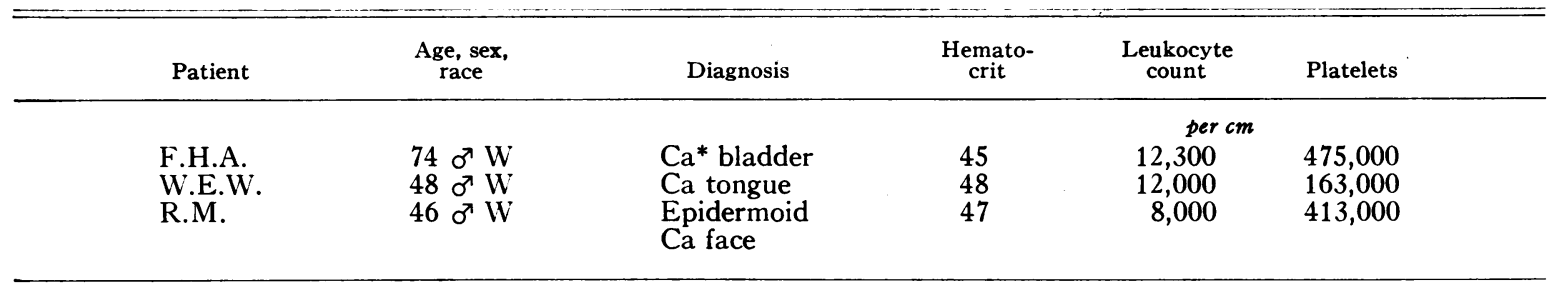

* $\mathrm{Ca}=$ cancer.

ferential counts were performed on all samples. Siliconized glassware was used, and cell separation procedures were performed in the cold. Leukocytes were isolated by a modification of the method of Fallon and associates as previously described $(13,14)$. Blood samples were allowed to sediment in a solution of equal volumes of $6 \%$ dextran in normal saline and $5 \%$ dextrose in water. After 30 minutes the leukocyte-rich supernatant was removed and spun for 10 minutes at $250 \mathrm{~g}$ in a refrigerated International type 2 centrifuge. $^{3}$ The supernatant was discarded, and the cell button was resuspended in normal saline before being subjected to thirty seconds of hypotonic lysis. The suspension was centrifuged again and the resulting cell button was washed twice in normal saline. After resuspension in normal saline a sample of the cell suspension was counted in the automatic cell counter, and smears were made for differential counting and radioautographs. A portion of the suspension containing a known number of leukocytes approximating $10^{8}$ was removed and centrifuged at $1,000 \mathrm{~g}$ for 10 minutes. The cell button was then stored at $0^{\circ} \mathrm{C}$. Comparison of the differential counts done on the whole blood with those done on the separated cells revealed no preferential loss of any type of leukocyte during the isolation procedure.

After all samples from an individual patient had been collected, they were dissolved in $0.5 \mathrm{ml}$ of $5 \%$ sodium hydroxide at $60^{\circ} \mathrm{C}$. Then $0.1 \mathrm{ml}$ of the resulting solution was added to $18 \mathrm{ml}$ of a scintillation mixture consisting of $70 \%$ toluene and $30 \%$ methanol containing $3 \mathrm{~g}$ of $2,5-$ diphenyloxazole (PPO) and $0.050 \mathrm{~g}$ of 1,4-bis-2-(4 methyl-5-phenyloxazolyl) benzene (dimethyl POPOP) per L. After a period of 48 hours at $-5^{\circ} \mathrm{C}$ the samples were counted in duplicate in a liquid scintillation spectrometer.4 Quenching was monitored by a channels ratio method; internal standards were used as necessary (15). Measurements are expressed in total counts per minute per $2 \times 10^{7}$ leukocytes. The zero time sample was considered background, and all subsequent samples were corrected by subtracting the zero time determination.

In order to correlate the liquid scintillation data with specific cell uptake, radioautography was also performed. Radioautographs were prepared from each whole blood sample and from each leukocyte concentrate

\footnotetext{
3 International Equipment Co., Boston, Mass.

4 Tri-Carb model 315 ex, Packard Instrument Co., La Grange, Ill.
}

used for the scintillation counting. Smears were made on clear gelatin-coated microscope slides, rapidly air dried, and fixed in Carnoy's solution. Kodak AR-10 stripping film was applied, and the slides were exposed for 6 weeks at $4^{\circ} \mathrm{C}$. The radioautographs were then developed, fixed, stained with Giemsa, and one or two thousand cell counts were done on each slide.

An estimate of the fraction of cells labeled by background only was obtained from the zero time radioautographs. If po refers to the observed fraction of labeled cells and $p_{b}$ to the fraction labeled by background, an estimate of the fraction of labeled cells on a given slide not labeled by background is $p$, (where $p=\left(p_{o}-p_{b}\right) /(1-$ $\left.\mathrm{p}_{\mathrm{b}}\right)$, when $\mathrm{p}_{\mathrm{b}} \mathrm{p}_{\mathrm{o}} \mathrm{p}$ was set equal to zero.

Chronic myelocytic leukemia. Twenty-four studies were performed on 13 patients with chronic myelocytic leukemia (CML). Two patients with myeloid metaplasia were also studied. All the CML patients demonstrated granulocytic hyperplasia of the bone marrow, granulocytic immaturity in the peripheral blood, low leukocyte alkaline phosphatase, and elevated serum vitamin $B_{12}$ levels. The $\mathrm{Ph}_{1}$ chromosome was present in the bone marrow cells of 12 patients. Three patients were studied while in relapse, partial remission, and remission. In relapse, the leukocyte count was greater than 60,000 per $\mathrm{mm}^{8}$, and there were immature granulocytes in peripheral blood. In partial remission, the leukocyte count was less than 60,000 but greater than 10,000 per $\mathrm{mm}^{3}$. In complete remission, the leukocyte count was less than 10,000 per $\mathrm{mm}^{3}$; there were no immature granulocytes in peripheral blood and no splenomegaly.

In vivo studies were carried out as above except that the dose of ${ }^{3} \mathrm{HTdR}$ ranged from 40 to $100 \mu \mathrm{c}$ per $\mathrm{kg}$. It has been possible to use the lower doses without affecting the resulting kinetic curve. Several patients have been studied more than once, but the total dose of ${ }^{3} \mathrm{HTdR}$ administered to any single patient has never exceeded $14 \mathrm{mc}$.

In vitro studies were carried out as follows: The leukocytes from $2 \mathrm{U}$ of blood were obtained by leukophoresis using the triple plastic bag technique. ${ }^{5}$ The leukocyte-rich plasma was centrifuged at $1,000 \mathrm{~g}$ for $15 \mathrm{~min}$ utes, and all but 30 to $40 \mathrm{ml}$ of the cell-free plasma was transferred into a connected bag. The leukocytes were resuspended in the remaining plasma and incubated with $3 \mathrm{mc}{ }^{3} \mathrm{HTdR}$ (SA, 1.9 c per mmole) per U. The incu- 
TABLE II

Summary of experiment to evaluate precision of liquid scintillation counting

\begin{tabular}{|c|c|c|}
\hline Patient & $\begin{array}{l}\text { Right ante- } \\
\text { cubital vein }\end{array}$ & $\begin{array}{l}\text { Left ante- } \\
\text { cubital vein }\end{array}$ \\
\hline & \multicolumn{2}{|c|}{$c p m / 2 \times 10^{7}$ cells } \\
\hline V.E. & $\begin{array}{l}267 \\
250 \\
231\end{array}$ & $\begin{array}{l}231 \\
228 \\
218\end{array}$ \\
\hline Average & 249.3 & 225.7 \\
\hline E.R. & $\begin{array}{l}65 \\
63 \\
64\end{array}$ & $\begin{array}{l}57 \\
61 \\
53\end{array}$ \\
\hline Average & 64.0 & 57.0 \\
\hline
\end{tabular}

bation was carried out at $37^{\circ}$ for 60 minutes with gentle agitation. ${ }^{6}$ After incubation the leukocytes were washed twice in cold autologous plasma and reinfused into the patient. Peripheral blood samples were collected and processed as above. Two-ml bone marrow aspirates were also obtained at various time intervals after infusion. The marrow samples were processed in the same way as the peripheral blood samples except that dextran-dextrose sedimentation was omitted. Samples of the whole blood, bone marrow aspirates, and the separated leukocytes were prepared for liquid scintillation counting and for radioautography as described above. However, since the analysis and interpretation of radioautographs, particularly of the mixed cell populations found in CML, are extremely complicated and will require prolonged study, only the results of the scintillation counting will be presented in detail along with preliminary data derived from analysis of the radioautographs.

Precision of methods. The precision of the liquid scintillation technique was evaluated by obtaining simultaneous blood samples from each antecubital vein of two study patients. Each sample was subdivided into three aliquots after hypotonic lysis. The aliquots were then processed independently, and the radioactivity of each was measured in duplicate. Table II summarizes these results.

There are two principal sources of variation in drawing and processing these samples. One source is in the comparison of aliquots from the same blood sample processed independently; the other is in the comparison of two different blood samples drawn from the same individual at the same time. In evaluating the precision of the liquid scintillation technique, it is convenient to analyze the logarithms of the counts rather than the counts themselves. Let $\mathrm{O}_{\mathbf{a}}{ }^{2}$ refer to the variance associated with the aliquots and $\mathrm{O}_{\mathrm{s}}{ }^{2}$ be the variance associated with drawing different samples from the same individual. With the data of Table II the estimates of these variances were calculated to be : $\mathrm{O}_{\mathrm{a}}{ }^{2}=5.7 \times 10^{-4}$, and $\mathrm{O}_{\mathrm{s}}{ }^{2}=8.1 \times 10^{-4}$.

${ }^{6}$ Dubnoff metabolic shaking incubator, Precision Scientific Co., Chicago, Ill.

\section{Results}

Normal individuals. The results obtained with liquid scintillation counting in these patients are shown in Figure 1. For comparative purposes, the vertical scale is normalized so that the peak radioactivity is taken as unity. Note that the relative level of radioactivity remains quite low in the peripheral blood until approximately 100 hours after labeling. Peripheral leukocyte radioactivity then sharply increases, reaching peak levels at about 168 hours. Base-line levels are approached by day, 18 .

In the radioautographic analysis, the number of grains in each cell was counted and the mean background count subtracted. All "negative" counts were set equal to zero. The corrections made in this way were quite small, since the mean background count was 2 grains per cell. The over-all labeling index reached a maximum of 0.33 at 168 hours after injection, as calculated from a count of 2,009 cells. Figure 2 shows the variation of labeling index as a function of time for the three major cell types. In these individuals, the results of

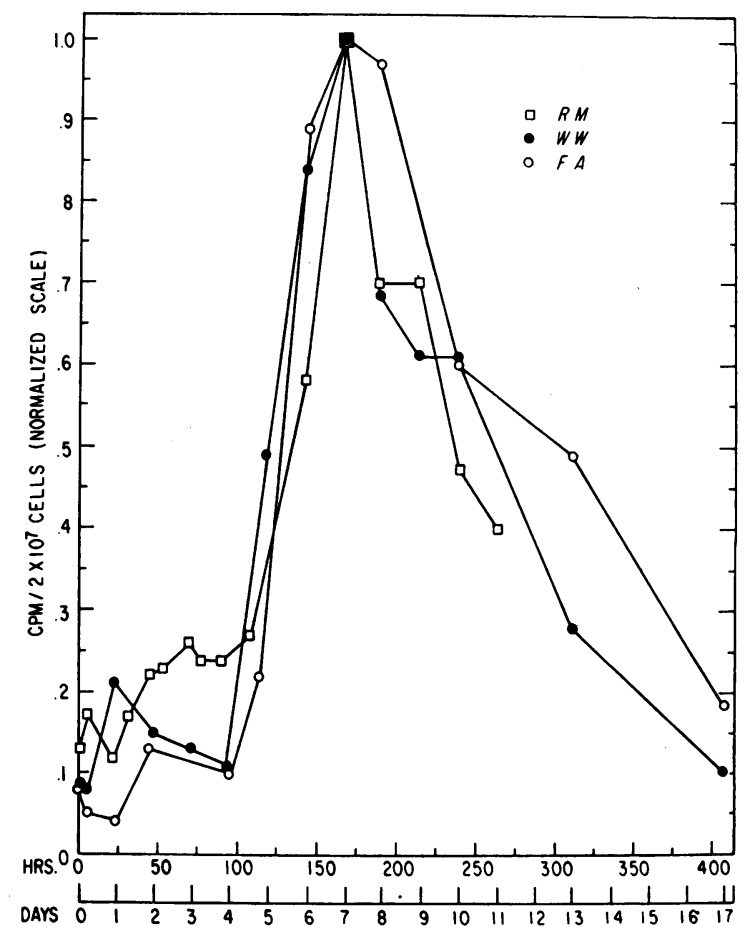

Fig. 1. LeUkocyte KINETIC CURVE for three NORMAL INDIVIDUALS AFTER ADMINISTRATION OF TRITIATED THYMIdiNE. Vertical scale has been normalized to per cent of maximal activity. 


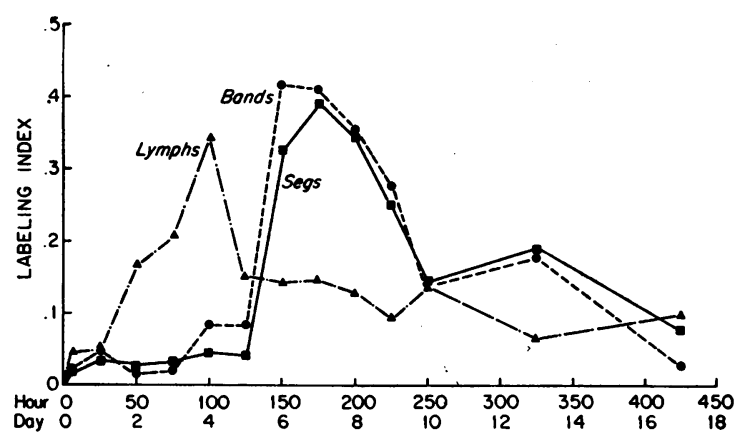

Fig. 2. VARIATION IN LABELING INDEX FOR VARIOUS CELL TYPES (F.H.A.)

the radioautographs in terms of per cent labeled cells compared favorably with the liquid scintillation data.

Chronic myelocytic leukemia. The leukocyte kinetic curves from nine CML patients in relapse are shown in Figure 3. Note the marked difference from the normal kinetic state. There is an initial high level of radioactivity followed by a large peak at 30 to 40 hours and a second major peak of activity at 120 to 144 hours. Occasionally, a small peak is seen between the two. It should be emphasized that the second major peak in the CML curve occurs 20 to 30 hours before the single peak in the hemopoietically normal individuals. Analysis of the radioautographs from two patients failed to reveal any significant change between the two major peaks with respect to differential count and total grain count. It appears then that after pulse labeling either two populations of labeled cells appear in the peripheral blood at different time intervals, or cells initially released at 30 to 48 hours leave the vascular compartment and return at a later time (120 to 144 hours).

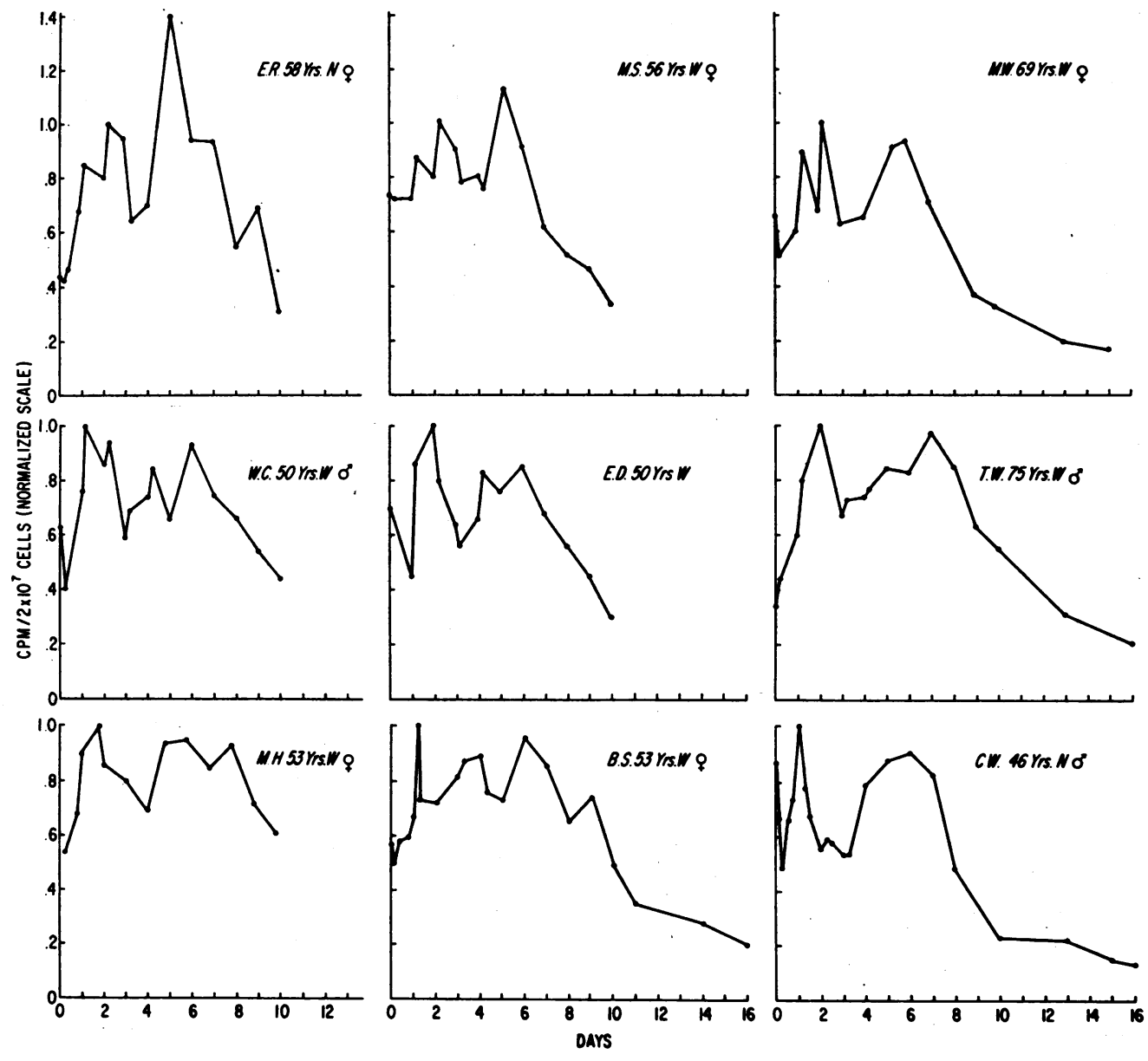

Fig. 3. Peripheral blood leukocyte kinetic curves in Nine patients with CML after the adMINISTRATION of ${ }^{8} \mathrm{HTDR}$. CML $=$ chronic myelocytic leukemia $;{ }^{3} \mathrm{HTdR}=$ tritiated thymidine. 


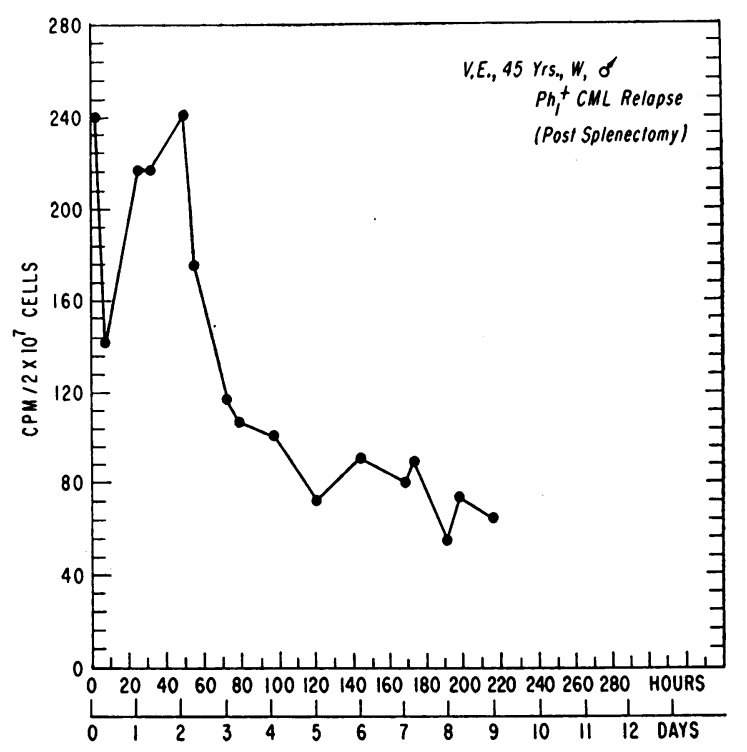

[illi. 4. Leukocyte kinetics in a patient with CML AFTER SPLENECTOMY. $\mathrm{Ph}_{1}=\mathrm{Ph}_{1}$ chromosome.

Figure 4 shows the in vivo leukocyte kinetics of a patient with typical $\mathrm{Ph}_{1}$ chromosome positive CML in relapse. The patient had undergone splenectomy 6 weeks before being studied. The absence of the second major peak, usually occurring at 120 to 144 hours, is striking.

Figure 5 illustrates results obtained from in

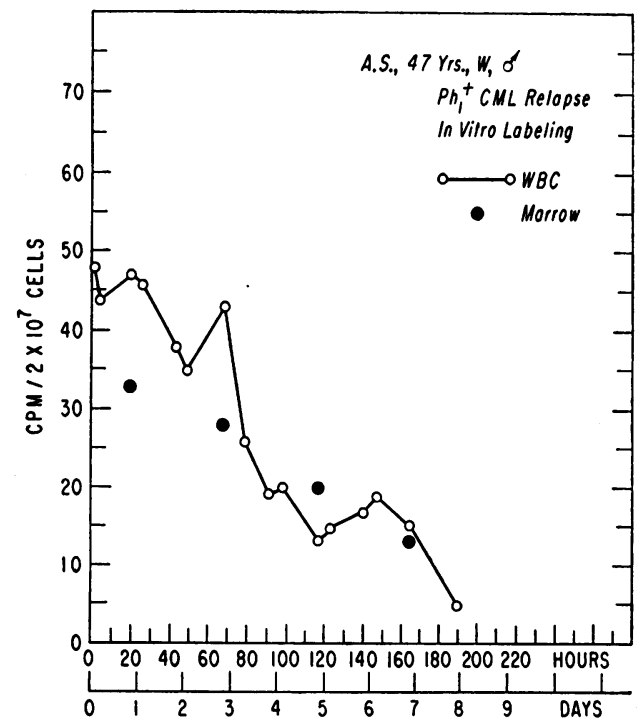

Fig. 5. Peripheral BloOd LeUkocyte and Marrow SPECIFIC ACTIVITY IN A PATIENT WITH CML AFTER THE INFUSION OF AUTOLOGOUS LEUKOCYTES LABELED WITH ${ }^{3} \mathrm{HT}$ DR. vitro labeling studies in CML. There is a gradual decline in peripheral blood leukocyte radioactivity, which is in agreement with previously published in vitro $\mathrm{DFP}^{32}$ studies (16). Of particular interest, however, was the presence of significant labeling of bone marrow leukocytes at every point studied. Radioautographs of the bone marrow aspirates revealed a small number of labeled mature granulocytes, indicating that some of the immature leukocytes labeled in vitro had undergone maturation. The specific activities in the bone marrow and peripheral blood leukocytes were approximately equivalent, although the leukocyte count in the bone marrow aspirate was fivefold greater than in the peripheral blood. This suggests that some leukocytes in the blood preferentially accumulate in the bone marrow. These data with a more detailed analysis have been reported previously (17).

The curves shown in Figure 6 demonstrate that the in vitro data obtained in the present study do not simply reflect cell damage. When damaged before reinfusion, a typical and reproducible disappearance curve resulted. In contrast to the curve shown in Figure 5, there is an initial rapid falloff of specific activity followed by a slow decline. The kinetics of damaged leukocytes in our studies are similar to analogous studies employing $\mathrm{DFP}^{32}$ (6).

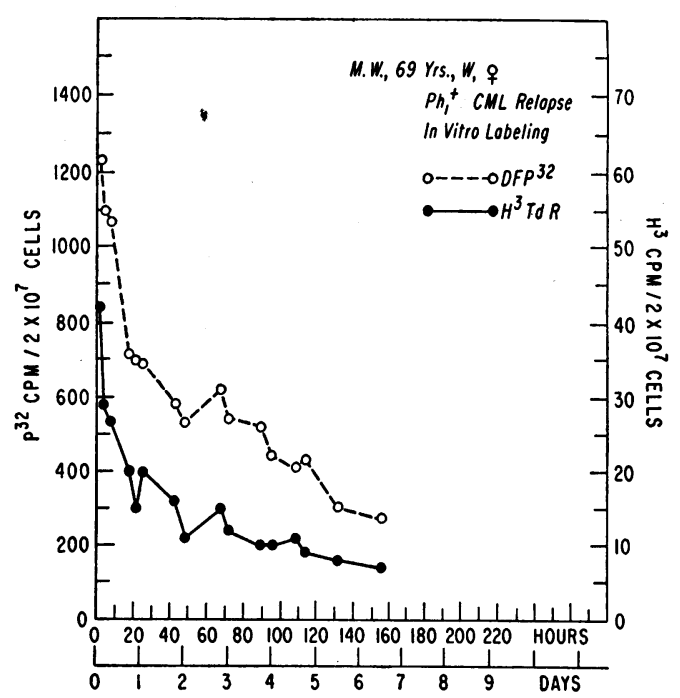

Fig. 6. Disappearance of autologous LeUkocytes LABELED WITH ${ }^{3} \mathrm{HT}$ DR AND DFP ${ }^{32}$ IN VITRO AND DELIBERATELY DAMAGED BEFORE INFUSION. DFP ${ }^{32}$-diisopropylfluorophosphate. 


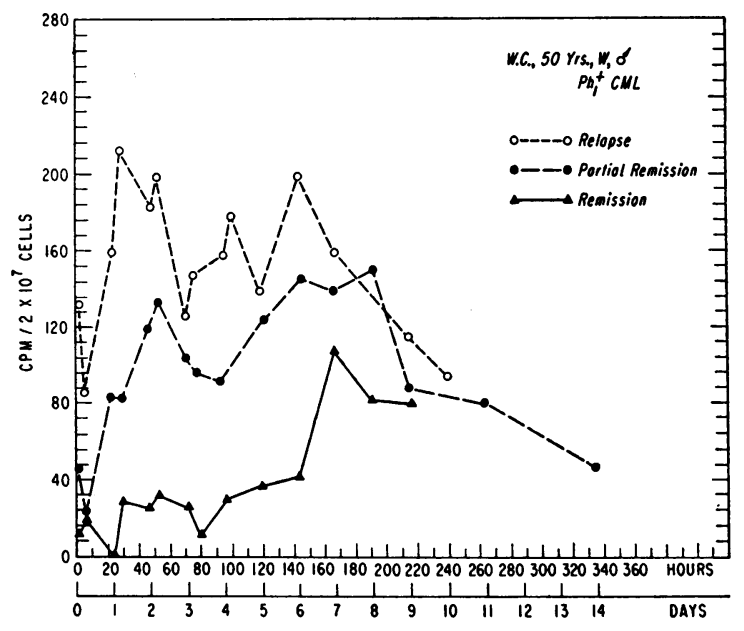

Fig. 7. COMPARISON OF LEUKOCYTE KINETIC CURVES in A PATIENT WITH CML IN RELAPSE, IN PARTIAL REMISSION, AND IN COMPLETE REMISSION.

Figure 7 describes the results obtained from a patient who was labeled on these separate occasions, i.e., in relapse, partial remission, and complete remission. Remission was achieved with busulfan. A similar change to a normal curve was also. observed in another patient treated with busulfan and in a patient after splenic irradiation. The change from abnormal to normal leukocyte dynamics appears to be gradual.

The results of studies in the two patients with myeloid metaplasia are shown in Figures 8 and 9. Patient S.M., who had an enlarged spleen, leukocytosis, and an immature leukocyte count differential had a curve similar to that seen in patients

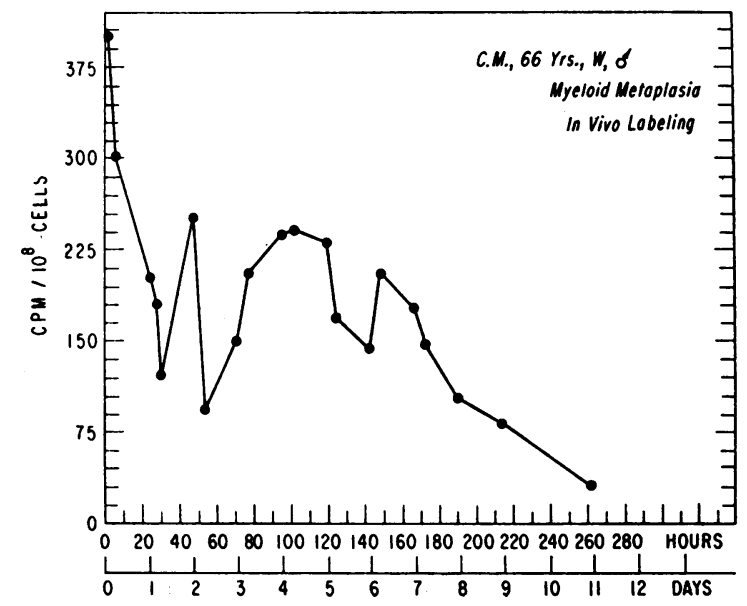

Fig. 8. Leukocyte kinetics in a patient with myeLOID METAPLASIA AND AN IMMATURE DIFFERENTIAL COUNT.

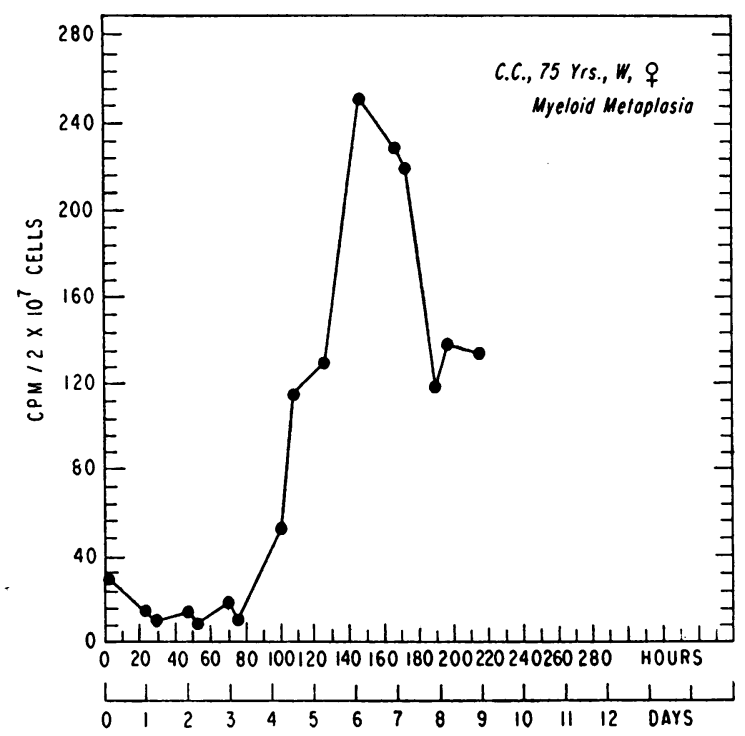

Fig. 9. Leukocyte kinetics in a patient with myeLOID METAPLASIA AND A NORMAL DIFFERENTIAL COUNT (POSTSPLENECTOMY).

with CML in relapse. His spleen was huge, extending below the pelvic brim and across the midline of the abdomen. The second patient (C.C.) had a leukocyte count of 50,000 per $\mathrm{mm}^{3}$, but without immature granulocytes in the peripheral blood. She had undergone splenectomy approximately 1 year before being studied. Her leukocyte kinetics appeared to be normal.

\section{Discussion}

The morphologic as well as the metabolic integrity of leukocytes separated from whole blood by dextran sedimentation and hypotonic lysis has previously been demonstrated (13). In addition, this isolation procedure does not result in the preferential loss of any class of leukocyte. Therefore, studies using both radioautographs and liquid scintillation counting of leukocytes obtained in this manner should be comparable.

Tritium is counted with an efficiency in the range of $20 \%$ with the liquid scintillation system employed in this study. This is to be contrasted with the very low and variable geometric efficiency of tritium in radioautographs of blood smears, which has been estimated to be less than $5 \%$ (18). Cronkite and co-workers have discussed the serious quantitative problems associated with use of tritium radioautography (19). Since the maximal 
range of tritium emissions is very short, the grain count overlying the cell depends on the thickness of the cell. If the thickness varies, cells with identical tritium contents will have different numbers of grain counts. This makes any attempt at quantitative evaluation of blood smears for radioautography very difficult. This problem does not exist when liquid scintillation counting is used, i.e., cell geometry is not a factor. In addition, results of leukocyte kinetic studies employing the liquid scintillation technique can be obtained rapidly; the results of an entire study are available within 2 days after collection of the last sample.

In addition to the longer time required to process radioautographs, there are problems in interpretation, particularly in regard to the evaluation of lightly labeled cells. When a grain threshold is used for background correction, these cells are likely to be excluded. This results in systematic errors in the estimation of mean grain counts, generation times, and percentage of labeled cells.

One of the unresolved problems in the use of ${ }^{3} \mathrm{HTdR}$ as an isotopic label in cell renewal systems is the effects of reutilization (20). Although reutilization has been demonstrated in both in vitro systems and in animals, its importance in the interpretation of leukocyte kinetics after a single tracer dose is still unsettled $(21,22)$. Even though tritium label has been found in regenerating liver of animals partially hepatectomized after being given ${ }^{3} \mathrm{HTdR}$, its incorporation into liver cells under ordinary circumstances may be quite different. This may be due to the fact that the liver is normally capable of clearing large quantities of thymidine from the blood (23). In studies from this laboratory reported elsewhere, no labeling of erythrocyte precursors was demonstrated in bone marrow radioautographs from patients with chronic myelocytic leukemia after the infusion of in vitro labeled autologous leukocytes (17). If reutilization occurs and is a random phenomenon, one would have expected the erythrocyte precursors in the bone marrow to have incorporated labeled DNA moieties or the thymine base locally available through the breakdown of the infused labeled cells. After the intravenous administration of tritiated thymidine, the label rapidly appears in both erythroid and myeloid precursors in the bone marrow; simultaneously, low levels of radioactivity appear in the peripheral blood leuko- cytes. The low level of radioactivity has been shown to be due to the presence of labeled monocytes and lymphocytes $(8,12)$. This finding has been confirmed in the present study.

The leukocyte kinetic curves obtained in normal individuals using scintillation counting are quite similar to those reported by Cronkite and co-workers (12) after radioautographic analysis. Cartwright, Athens, and Wintrobe, in a recent analytical review of granulocyte kinetics in normal individuals, divided the in vitro leukocyte curve obtained with $\mathrm{DFP}^{32}$ into three phases (5). Figure 10 compares the $\mathrm{DFP}^{32}$ results with an average of the scintillation data reported here. It is not possible from the $\mathrm{DFP}^{32}$ data to determine the point at which the first daughter cells of the initially labeled myelocytes begin to appear in the peripheral blood. However, in the present study. using a DNA label, the lag period of 100 hours before the rapid rise of specific activity in the peripheral blood is the period during which unlabeled mature granulocytes and metamyelocytes (after maturation) move into the blood from the bone marrow. This value is in the range obtained from radioautographic analysis (8). The sharp rise in radioactivity is due to the entrance into the circulation of the first descendants of myelocytes, which were in the DNA synthesis phase when the radioisotope was administered. Therefore, there are enough nonproliferating granulocytes in the marrow to supply the peripheral blood under normal circumstances for 100 hours. Since the $t_{1}$ for

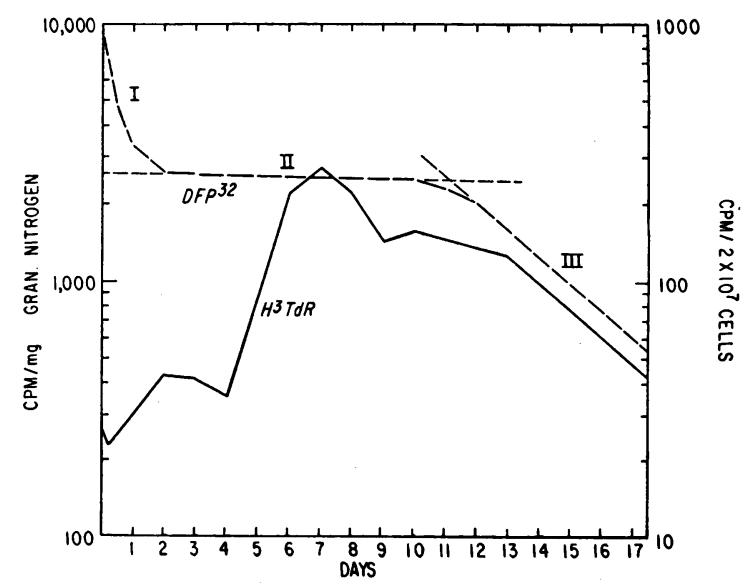

Fig. 10. Comparison of REPORTEd DFP ${ }^{32}$ (5) WITH AN AVERAGE OF THE LIQUID SCINTILLATION DATA REPORTED IN THIS PAPER. Gran. = granulocyte. 
circulating granulocytes is estimated at 6.6 hours (24) and the normal leukocyte count is in the range of 7,000 per $\mathrm{mm}^{3}$, the bone marrow "reserve" can be calculated to contain $2.7 \times 10^{11}$ cells. This figure is one of the same order of magnitude as reported by Donohue and co-workers (25).

The median times required for a myelocyte to divide, mature, and enter the blood, as calculated from the data obtained from these patients, are $7.5,8.5$, and 8.7 days, respectively. Cartwright and associates (5) have reported a value of 11.4 days for the mean time for a myelocyte to divide, mature, and enter the peripheral blood. On closer examination, this value of 11.4 days represents that point in time where the daughter cells of the second generation myelocytes enter the peripheral blood. It is to be noted that this point in time corresponds to the end of a "shoulder," which appears to be present in two of the three patients studied.

The final decline of peripheral blood radioactivity in the curves presented here appears to have $\mathrm{a}_{\frac{1}{2}}$ of 3 days. The final exponential decline in leukocyte $\mathrm{DFP}^{32}$ radioactivity also has a $t_{1}$ of 3 days and is thought to represent the entrance into the blood of granulocytes originating from a second myelocyte division. Then the $t_{1}$ of 3 days approximates a myelocyte generation time.

The models that have been proposed for leukocyte kinetics in normal individuals are fairly simple, although the elucidation of detail can be a complex and formidable task (26). The accepted concept is that granulocytes develop and mature in the bone marrow and then enter the peripheral blood randomly. According to this model, leukocytes sojourn in the marrow for a period of time determined by a probability distribution, after which they enter and circulate in the peripheral blood. After circulating there some time, they leave the vascular tree. In this model the circulating and marginated pools are considered to be a single pool. It is to be emphasized that no further pools are necessary to explain the data presented in this paper. The same can be said for the data obtained with $\mathrm{DFP}^{32}$ (24). In chronic myelocytic leukemia, however, other pools are necessary to obtain a model in agreement with the data.

In contrast to normal individuals there is an initial high level of peripheral blood leukocyte ra- dioactivity in patients with CML, which is presumably due to instantaneous labeling of circulating immature cells. The peak that follows at 2 days has been reported by investigators who used ${ }^{3} \mathrm{HTdR}$ radioautographs and inorganic ${ }^{32} \mathrm{P}$ in the studies of leukocyte kinetics in this disease $(2,11)$. The level of this peak is probably due to the result of a number of factors, including the influx of labeled and unlabeled cells, loss of labeled cells, and cell division. In contrast to the earlier investigations, our studies using liquicl scintillation counting clearly establish the existence of another major peak at 5 to 10 days.

Studies with $\mathrm{DFP}^{32}$ have indicated that in vitro labeled leukocytes disappear slowly from the blood of patients with CML and myeloid metaplasia. Other kinetic similarities between CML and myeloid metaplasia have also been reported $(2,16,27)$. Our studies confirm these earlier findings.

The usual CML patients with elevated leukocyte counts and immature leukocytes in the peripheral circulation have at least two peaks of radioactivity in the peripheral blood after the administration of ${ }^{3} \mathrm{HTdR}$. In the absence of the spleen in one patient with CML, the second major peak did not appear. Unfortunately, we have not yet had the opportunity to confirm these observations in other similar patients. From the studies in the two patients with myeloid metaplasia, leukocytosis alone, without immaturity and in the absence of the spleen, results in a normal kinetic pattern. The consideration of these findings in relation to our previous results in hematologically normal individuals gives rise to the model of granulocyte kinetics in CML idealized in Figure 11. The essential elements of this model include a large spleen compartment and the ability of a granulocyte in the peripheral blood to return to the bone marrow. The two major peaks of radioactivity in the peripheral blood imply a varying input of labeled cells, as has been suggested by Fliedner, Cronkite, Killmann, and Bond (28). There are at least three possibilities as to the origins of these "populations": 1) successive release from the bone marrow, 2) successive release from the spleen and other organs, and 3) some combination of these. Our results in the patient with CML who had been splenectomized would favor the third possibility. It is possible that immature leukocytes are released from the marrow at 30 to 40 hours 


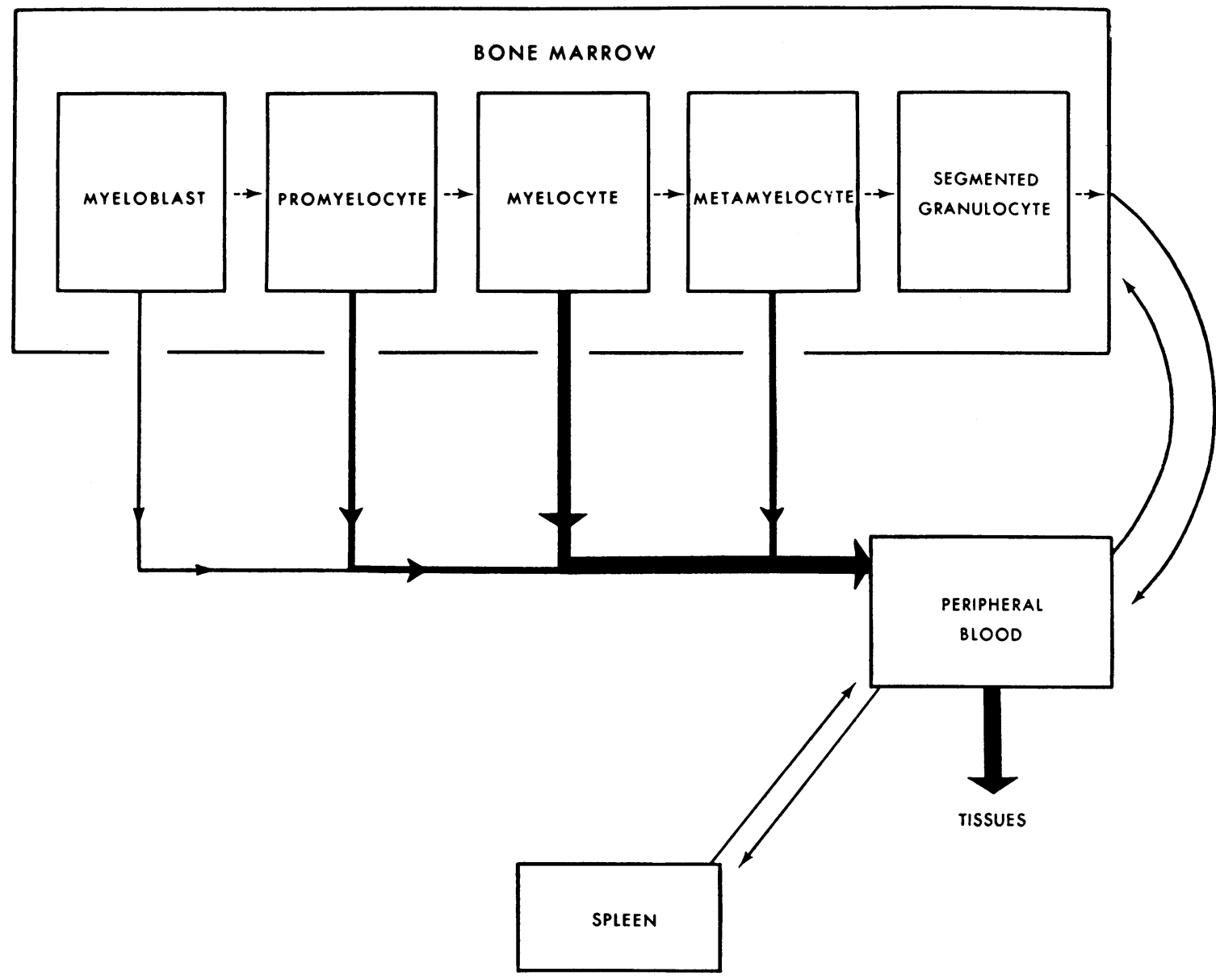

Fig. 11. Idealized model of leukocyte kinfetics in patients with CML.

after labeling, enter the spleen, sojourn there for some time, re-enter the vascular tree, and return to the marrow. In addition, as Clarkson. Ota, O'Connor, and Karnofsky have suggested on the basis of studies with direct infusion of ${ }^{3} \mathrm{HTdR}$, the enlarged spleen may be a major hematopoietic center in CML (29). This has long been suspected on clinical grounds. We have no data from our current investigation bearing on this hypothesis.

\section{Summary}

A technique using liquid scintillation counting for the study of leukocyte kinetics with tritiated thymidine $\left({ }^{3} \mathrm{HTdR}\right)$ in man has been described.

The peripheral blood granulocyte radioactivity in the hematologically normal inclividual is characterized by a single peak at approximately 6 to 7 days. There is a low level of radioactivity in the peripheral blood leukocytes for approximately 100 hours, after which there is a rapid rise of specific activity due to the influx into the circulation of the first descendants of myelocytes, which were in the DNA synthesis phase when the radioisotope was administered. The median time required for a myelocyte to divide, mature, and enter the blood was $7.5,8.5$, and 8.7 days, respectively.

In contrast to normal individuals, patients with chronic myelocytic leukemia (CML) demonstrate an immediate high level of peripheral blood leukocyte radioactivity, followed by peaks at 30 to 40 hours and at 120 to 144 hours. This is interpreted as either the release of different cell populations or the return to the blood of leukocytes released at an earlier time.

Studies with reinfused labeled autologous leukocytes indicate that some leukocytes in the periph- 
eral blood return to the bone marrow in patients with CML.

From the results of these studies it is suggested that in patients with CML, immature leukocytes entering the vascular tree have multiple sojourns in bone marrow, spleen, and blood.

\section{Acknowledgments}

We are grateful to Karen L. Shirley and Ada Brooks for their technical assistance and to Jane A. Menken and Alroy M. Smith for programming assistance.

\section{Appendix}

It is known that the leukocyte loss from the peripheral blood in normal individuals follows an exponential falloff with a $t_{1}$ estimated to be 6.6 hours (24). With these facts, the rate of flow of labeled cells out of the bone marrow can be estimated from the change of radioactivity in the peripheral blood. A derivation of the necessary relations is as follows. Let $c(t)$ be the observed concentration of radioactivity in the peripheral blood (measured in units of counts per minute per $10^{7}$ cells), and let $s(t)$ be the rate of flow of radioactive label into the peripheral blood (measured in units of counts per minute per $10^{7}$ cells per day). Then the rate of change of radioactivity in the peripheral blood is the rate of flow from the marrow minus the loss from the peripheral blood. However, the loss is proportional to concentration, the factor of proportionality being $0.693 / \mathrm{t}_{3}=$ 2.52 days, where $t_{\frac{1}{2}}=6.6$ hours. In equation form this is : $\mathrm{s}(\mathrm{t})=[\mathrm{dc}(\mathrm{t})] / \mathrm{dt}-2.52 \mathrm{c}(\mathrm{t})$.

The results of our calculations on patient data indicate that the flow rate has a peak at about 1 week. In addition, patients F.A. and W.W. exhibited a period during which the flow rate remained nearly stationary. This is in accord with the model of Warner and Athens (26), which postulates a recycling of myelocytes, or possibly a second population of cells. Further data are needed to confirm the existence of a "shoulder" in the flow curve and to elucidate its meaning.

Simulation of theoretical model of leukocyte kinetics. In this section we discuss our investigation of leukocyte kinetics using simulation procedures. ${ }^{7}$ These simulation procedures were based on the three compartment system shown in Figure 11. The results of our theoretical investigations suggest the hypotheses that 1 ) there may be two populations of leukocytes emerging from the marrow for CML patients, as has also been proposed for hematopoietically normal individuals, and 2) the spleen is a major hematopoietic organ in CML. Without these two hypotheses, we have not been able to duplicate the

7 Although one can formally set up the coupled integral equations governing the kinetic systems, these can only be solved by numerical analysis. The simulation techniques enable one to also obtain numerical results, but these are obtained in a more convenient way. qualitative characteristics of CML leukocyte kinetics. The simulation model also included return of leukocytes to the marrow and the possibility of sequestration of cells in the spleen.

The technique of simulation has been to follow the time history of a single leukocyte originating in each hematopoietic organ, replicating the process 2,000 times, and keeping a record of the fate of the population of leukocytes at fixed times of observation in the peripheral blood. This corresponds to following labeled leukocytes by drawing samples from the peripheral blood. As an example of the simulation process let us consider a single leukocyte originating in the marrow. It is assigned a random time of exit from the marrow in accordance with a normal probability distribution (i.e., two parameters, a mean and standard deviation, are needed to specify the statistical characteristics of the population). The sojourn time of the leukocyte in the peripheral blood is also random, but in accordance with the exponential probability distribution ${ }^{8}$; i.e., the probability that a single sojourn time is greater than $t$ is $\exp (-t / 0)$, where 0 is the mean sojourn time. The leukocyte emerging from the peripheral blood then has a probability $p_{m}$ of returning to the marrow, a probability $\mathrm{p}_{s}$ of being sequestered in the spleen, or a probability $\mathrm{pd}_{\mathrm{d}}$ of loss by destruction or migration into tissues. The probabilities are taken to add to unity. The sojourn time probability distribution in the spleen is also assumed to be normal, but with different parameters than either of the marrow compartments. If, after the leukocyte leaves the peripheral blood, it enters the marrow or spleen, it sojourns there for an amount of time that has a normal probability distribution characteristic of the organ (rather than one that reflects the age of the leukocyte). Finally, the leukocyte is lost during one of its sojourns in the peripheral blood.

To explain the high initial uptake of label in CML patients, we had to postulate the presence of circulating cells synthesizing DNA in the peripheral blood. These cells were assumed to be rapidly lost so as to produce an exponential decay $\exp (-t / T)$, where $T$ is the mean lifetime of the circulating myelocyte.

The theoretical model is completely characterized by 13 parameters. Two compartments in the marrow, each having different normal probability distributions, require 4 parameters; the normal spleen sojourn time adds another 2; the peripheral blood exponential sojourn times require 2 parameters; the transition probabilities $\mathrm{p}_{\mathrm{d}}, \mathrm{p}_{\mathrm{s}}$, and $\mathrm{p}_{\mathrm{m}}$ add 2 more independent parameters; finally, one must include 3 additional parameters, which give the relative number of leukocytes labeled initially in the peripheral blood, in the spleen, and the two compartments of the marrow. The mean sojourn time in the marrow was chosen as 2 days, whereas that in the spleen was chosen as 6 days. These times correspond to the times of peak outputs observed in most of our CML patients. The mean sojourn in the second marrow compartment

8 Although this distribution has been verified for hematopoietically normal individuals, it remains as a tentative hypothesis for CML patients. 
was chosen to be 4 days, since the output in the peripheral blood appeared to be high between the times of peak output. The standard deviations of the sojourn distributions were chosen so that the period of major output coincided with observed data; the mean sojourn time in the peripheral blood was chosen so that the amount of radioactivity after 15 days was approximately at base-line levels. Figure 12 shows a graph of the radioactivity in the peripheral blood. The parameters characterizing this particular model are: $\mu_{\mathrm{m}_{1}}=$ mean sojourn time in the marrow, 2 days; $\mu_{m_{2}}=$ mean sojourn time in the second compartment of the marrow, 4 days; $\mu_{\mathrm{s}}=$ mean sojourn time in the spleen, 6 days; $\mathrm{o}_{\mathrm{m}_{1}}=$ standard deviation of marrow sojourn time, $\frac{1}{2}$ day; $\mathrm{o}_{\mathrm{m}}=$ standard deviation of sojourn time in the second marrow compartment, 1 day; $o_{s}=$ standard deviation of spleen sojourn time, $\frac{1}{2}$ day; $\mathrm{T}=$ mean decay time for cells initially labeled in the peripheral blood, 2 days; $0=$ mean sojourn time in the peripheral blood, 0.8 day; $\mathrm{p}_{\mathrm{m}}=$ probability of return to the marrow (from the peripheral blood), 0.6; $\mathrm{p}_{\mathrm{d}}=$ probability of disintegration in the peripheral blood, 0.4 ; and $\mathrm{p}_{\mathrm{s}}=$ probability of sequestration in the spleen (of a cell from the peripheral blood), 0. The initial number of leukocytes labeled in the peripheral blood was 1,000 ; that in the marrow was 2,000 ; that in the second compartment of the marrow was 1,000 ; and that in the spleen was 1,000 .

With the large number of parameters at our disposal, it is to be expected that we can duplicate observed data fairly well. Therefore, the parameters that have been chosen to produce Figure 11 cannot be taken as being anything more than suggestive. There are several points that emerge from an examination of the output of the model with different parameters. First, there must be a considerable amount of hematopoietic production in the spleen to account for the relatively large peak that usually appears at 6 days in the CML patients in relapse. We have not been able to reproduce a large peak at 6 days by assuming hematopoietic production in the marrow only, with subsequent large circulation to the spleen.

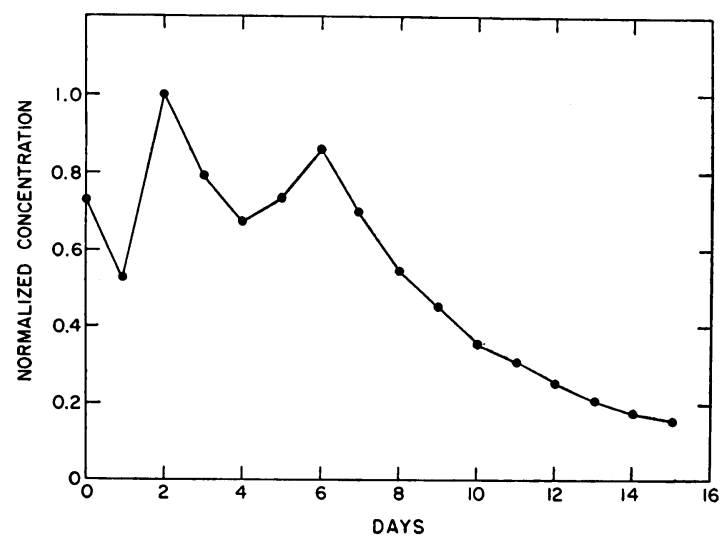

Fig. 12. Simulated Leukocyte kinetic curve in patients with CML. This curve is based on two compartments in the marrow and one in the spleen.
Second, the model requires a substantial amount of leukocyte "leakage" from the peripheral blood to the marrow. This is in accord with previous findings (2). Third, the mean time of leukocytes in the peripheral blood for a single sojourn does not appear to be in any way a critical one for our mathematical model. Almost similar results can be obtained taking 0 to be in the range of 0.3 to 1.0 day. Likewise, the precise form of the sojourn time distribution is not a critical one. Fourth, we were unable to duplicate some of the minor narrow irregular peaks observed in several CML patients (Figure 3 ) occurring between the major peaks at 2 and 6 days. Although these peaks might be due to sampling of instrumental artifacts, there is a possibility that they reflect other hemopoietically active centers. Further work to confirm or contradict this possibility would be of considerable interest. Finally, the value of $\mathrm{p}_{\mathrm{s}}$ for the curve of Figure 12 was 0 . Similar curves can be obtained by letting $\mathrm{p}_{\mathrm{s}}$ range up to 0.2 and reducing the combination of $\mathrm{p}_{\mathrm{d}}$ and $\mathrm{p}_{\mathrm{m}}$.

There are many assumptions contained in our model, which at this time have not been verified experimentally. For example, we have assumed that the characteristics of a leukocyte originating in the spleen are the same as those of a leukocyte originating in the marrow. Our model presupposes that the leukocyte loss is random without regard to age. A further assumption is that the predominant leukocyte loss is from the peripheral blood. In spite of the arbitrary nature of many of these assumptions, we believe that the model accounts for the principal features observed in the data and that the incorrectness of any of the assumptions cited in this paragraph will not invalidate our major conclusion that the peaks observed in the data correspond to discharges from hemopoietically active organs.

\section{References}

1. Ottesen, J. On the age of human white cells in peripheral blood. Acta physiol. scand. 1954, 32, 75.

2. Perry, S., C. G. Craddock, Jr., and J. S. Lawrence. Rates of appearance and disappearance of white blood cells in normal and in various disease states. J. Lab. clin. Med. 1958, 51, 501.

3. Athens, J. W., S. O. Raab, O. P. Haab, A. M. Mauer, H. Ashenbrucker, G. E. Cartwright, and M. M. Wintrobe. Leukokinetic studies. III. The distribution of granulocytes in the blood of normal subjects. J. clin. Invest. 1961, 40, 159.

4. Hamilton, L. D. Carbon ${ }^{14}$ labeling of DNA in studying hematopoietic cells in The Kinetics of Cellular Proliferation, 1st ed., F. Stohlman, Jr., Ed. New York, Grune \& Stratton, 1959, p. 151.

5. Cartwright, G. E., J. W. Athens, and M. M. Wintrobe. The kinetics of granulopoiesis in normal man. Blood 1964, 24, 780.

6. Athens, J. W., S. O. Raab, O. P. Haab, D. R. Boggs, H. Ashenbrucker, G. E. Cartwright, and M. M. Wintrobe. Leukokinetic studies. X. Blood granu- 
locyte kinetics in chronic myelocytic leukemia. J. clin. Invest. 1965, 44, 765.

7. Taylor, J. H., P. S. Woods, and W. L. Hughes. The organization and duplication of chromosomes as revealed by autoradiographic studies using tritium-labeled thymidine. Proc. nat. Acad. Sci. (Wash.) 1957, 43, 122.

8. Bond, V. P., T. M. Fliedner, E. P. Cronkite, J. R. Rubini, and J. S. Robertson. Cell turnover in blood and blood-forming tissues studied with tritiated thymidine in The Kinetics of Cellular Proliferation, 1st ed. F. Stohlman, Jr., Ed. New York, Grune \& Stratton, 1959, p. 188.

9. Mauer, A. M., and V. Fisher. In vivo study of cell kinetics in acute leukaemia. Nature (Lond.) 1963, 197, 574.

10. Reichard, P., and B. Estborn. Utilization of desoxyribosides in the synthesis of polynucleotides. J. biol. Chem. 1951, 188, 839.

11. Killmann, S. A., E. P. Cronkite, J. S. Robertson, T. M. Fliedner, and V. P. Bond. Estimation of phases of the life cycle of leukemic cells from labeling in human beings in vivo with tritiated thymidine. Lab. Invest. 1963, 12, 671.

12. Cronkite, E. P., J. M. Fliedner, V. P. Bond, J. R. Rubini, G. Brecher, and H. Quastler. Dynamics of hemopoietic proliferation in man and mice studied by $\mathrm{H}^{3}$-thymidine incorporation into $\mathrm{DNA}$. Progr. nucl. Energy (Biol.) 1959, 2, 92.

13. Fallon, H. J., E. Frei III, J. D. Davidson, J. S. Trier, and D. Burk. Leukocyte preparations from human blood: evaluation of their morphologic and metabolic state. J. Lab. clin. Med. 1962, 59, 779.

14. Marsh, J. C., and S. Perry. Thymidine catabolism by normal and leukemic human leukocytes. J. clin. Invest. 1964, 43, 267.

15. Baillie, L. A. Determination of liquid scintillation counting efficiency by pulse height shift. Int. J. appl. Radiat. 1960, 8, 1.

16. Cartwright, G. E., J. W. Athens, O. P. Haab, S. O. Raab, D. R. Boggs, and M. M. Wintrobe. Blood granulocyte kinetics in conditions associated with granulocytosis. Ann. N. Y. Acad. Sci. 1964, 113, 963.

17. Moxley, J. 'H., S. Perry, G. H. Weiss, and M. Zelen. Return of leukocytes to the bone marrow in chronic myelogenous leukaemia. Nature (Lond.) 1965, 208, 1281.
18. Lajtha, L. G., and R. Oliver. The application of autoradiography in the study of nucleic acid metabolism. Lab. Invest. 1959, 8, 214.

19. Cronkite, E. P., V. P. Bond, T. M. Fliedner, J. R. Rubini, and S. A. Killmann. Studies on the life cycle of normal and neoplastic leukocytes by labeling DNA with tritiated thymidine. Proceedings of the Ninth International Congress of Radiology (Munich), B. Rajewsky, Ed. Stuttgart, Georg Thieme, 1961, p. 894.

20. Discussion of the reutilization of DNA and DNA breakdown products in The Kinetics of Cellular Proliferation, 1st ed., F. Stohlman, Jr., Ed. New York, Grune \& Stratton, 1959, p. 110.

21. Feinendegen, L. E., V. P. Bond, E. P. Cronkite, and W. L. Hughes. RNA turnover in normal rat bone marrow. Ann. N. Y. Acad. Sci. 1964, 113, 727.

22. Bryant, B. J. Reutilization of leukocyte DNA by cells of regenerating liver. Exp. Cell Res. 1962, 27, 70.

23. Rubini, J. R., E. P. Cronkite, V. P. Bond, and T. M. Fliedner. Metabolism and fate of tritiated thymidine in man. J. clin. Invest. 1960, 39, 909.

24. Mauer, A. M., J. W. Athens, H. Ashenbrucker, G. E. Cartwright, and M. M. Wintrobe. Leukokinetic studies. II. A method for labeling granulocytes in vitro with radioactive diisopropylfluorophosphate $\left(\mathrm{DFP}^{32}\right)$. J. clin. Invest. 1960, 39, 1481.

25. Donohue, D. M., R. H. Reiff, M. L. Hanson, Y. Betson, and C. A. Finch. Quantitative measurement of the erythrocytic and granulocytic cells of the marrow and blood. J. clin. Invest. 1958, 37, 1571.

26. Warner, H. R., and J. W. Athens. An analysis of granulocyte kinetics in blood and bone marrow. Ann. N. Y. Acad. Sci. 1964, 113, 523.

27. Walker, R. I., J. C. Herion, W. B. Herring, and J. G. Palmer. Leukocyte kinetics in hematologic disorders studied by DNA-phosphorus labeling. Blood 1964, 23, 795.

28. Fliedner, T. M., E. P. Cronkite, S. A. Killmann, and V. P. Bond. Granulocytopoiesis. II. Emergence and pattern of labeling of neutrophilic granulocytes in humans. Blood 1964, 24, 683.

29. Clarkson, B., K. Ota, A. O'Connor, and D. A. Karnofsky. Production of granulocytes by the spleen in chronic granulocytic leukemia (CGL) (abstract). J. clin. Invest. 1963, 42, 924. 